\title{
Challenges and Strategies for Improving COPD Primary Care Services in Quebec: Results of the Experience of the COMPAS+ Quality Improvement Collaborative
}

\author{
Brigitte Vachon (1D ${ }^{1,2}$, Guylaine Giasson $\mathbb{1}^{3}$, Isabelle Gaboury $\mathbb{D}^{3,4}$, Dina Gaid (1D), \\ Véronique Noël De Tilly ${ }^{5}$, Lise Houle ${ }^{6}$, Jean Bourbeau ${ }^{7}$, Marie-Pascale Pomey (D) $^{8,9}$ \\ 'School of Rehabilitation, Faculty of Medicine, Université de Montréal, Montreal, Quebec, Canada; ${ }^{2}$ Centre de recherche du CIUSSS de l'Est de \\ Montréal, Montreal, Quebec, Canada; ${ }^{3}$ Centre de recherche Charles-Le Moyne, Longueuil, Quebec, Canada; ${ }^{4}$ Department of Family and Emergency \\ Medicine, Faculty of Medicine and Health Sciences, Université de Sherbrooke, Sherbrooke, Quebec, Canada; ${ }^{5}$ Convergence Santé, Montreal, Québec, \\ Canada; ${ }^{6}$ Institut national d'excellence en santé et en services sociaux (INESSS), Montreal, Quebec, Canada; ${ }^{7}$ Center of Innovative Medicine, Research \\ Institute of the McGill University Health Centre, Montreal, Quebec, Canada; ${ }^{8}$ Public Health School, Department of Management, Evaluation and \\ Health Policy, Faculty of Medicine, Université de Montréal, Montreal, Quebec, Canada; ${ }^{9}$ Centre de recherche de Centre hospitalier universitaire de \\ I'Université de Montréal, Montreal, Quebec, Canada
}

Correspondence: Brigitte Vachon, School of Rehabilitation, Faculty of Medicine, Université de Montréal, CP 6I28 Succursale Centre-Ville, Montreal, Quebec, H3C 3J7, Canada, Tel +I 5 I4 343-2094, Email brigitte.vachon@umontreal.ca

Introduction: Management of chronic obstructive pulmonary disease (COPD) remains a challenge in primary care and multiple barriers can limit implementation of COPD guidelines. Since 2016, a quality improvement (QI) collaborative, called COMPAS+, has been implemented across the province of Quebec (Canada) to support improvement of chronic disease management in primary care. The aim of this study was to describe the main COPD quality problems reported by participating teams and the strategies they proposed and implemented to improve COPD primary care services in Quebec.

Methods: Sixteen sites in four different regions of Quebec were engaged in the COMPAS+ intervention to improve primary care services delivered to people living with COPD. A total of 14 workshop reports, 31 QI action plans and 4 regional final reports underwent content analysis. Key COPD quality problems were first identified and, for each of them, root causes were classified according to the domains and constructs of the Consolidated Framework for Implementation Research. Proposed strategies were organized according to the intervention function types described in the Behavior Change Wheel.

Results: Four key COPD quality problems were identified: 1) lack of organization/coordination of COPD services, 2) lack of screening services coordination, 3) lack of interprofessional communication and collaboration and 4) lack of treatment adherence. Main root causes explaining these quality gaps were 1) lack of awareness of COPD, 2) lack of professional knowledge, 3) lack of definition of professional roles, 4) lack of resources and tools for COPD prevention, diagnosis, and follow-up, 5) lack of communication tools, 6) lack of integration of the patient-as-partner approach, and 7) lack of adaptation of patient education to their specific needs. Multiple strategies were proposed to improve healthcare professionals' education and interprofessional collaboration and communication.

Conclusion: QI collaborative activities can support achieving understanding of QI challenges healthcare organizations face to improve COPD services.

Keywords: COPD, quality of care, primary care, quality improvement collaborative, interprofessional collaboration

\section{Introduction}

Chronic obstructive pulmonary disease (COPD) is highly prevalent and one of the leading cause of death worldwide. ${ }^{1}$ An estimated two million Canadians (10\%) live with COPD, and its prevalence is increasing by $2.5 \%$ per year as the population ages. ${ }^{2}$ Yet people are often unaware of COPD. ${ }^{3}$ Furthermore, it is still largely underdiagnosed ${ }^{4}$ and associated 
with frequent emergency department visits, ${ }^{5}$ unplanned hospitalizations, ${ }^{6}$ high readmission rates, ${ }^{5}$ work and daily activity limitations ${ }^{7}$ and a significant negative impact on the quality of life of individuals and their families and caregivers. ${ }^{6}$

Primary care services play a prominent role in COPD diagnosis and management as they monitor disease progression, exacerbations, medication adherence and individual action plans. ${ }^{8}$ However, patients managed exclusively by primary care physicians are less likely to receive treatment adherent to Global Initiative for Chronic Obstructive Pulmonary Disease (GOLD) recommendations. ${ }^{7}$ A recent review showed that the parts of the COPD recommendations adopted by general practitioners vary considerably between practitioners. ${ }^{9}$ Several barriers limit use of guidelines such as professionals' lack of awareness of them, lack of availability of spirometry, improper selection of pharmacotherapy options and lack of smoking cessation counseling. ${ }^{10}$ Many practice gaps have been identified regarding the use of spirometry to diagnose COPD, vaccination and smoking cessation. ${ }^{9}$ Primary care practice audits in Canada ${ }^{11}$ demonstrated that about two-thirds of patients with COPD receive inadequate pharmacotherapy, including both underuse of long-acting bronchodilators in moderate and severe patients and overuse of inhaled corticosteroids in mild patients. Ineffective implementation of evidence-based treatments, including preventive measures, can lead to disease progression, in turn reducing lung functions, deteriorating overall health status, increasing the incidence of COPD-related hospitalizations and raising healthcare utilization. ${ }^{12,13}$

Primary care services also have a critical role to play in developing patients' self-management skills. ${ }^{8}$ Selfmanagement programs, such as the "Living well with COPD" program (www.livingwellwithcopd.com), developed in the province of Quebec, Canada, and recognized internationally, have been shown effective in improving patient empowerment, self-efficacy, and quality of life and in decreasing the number of severe exacerbations requiring emergency department visits and hospital admissions. ${ }^{14-16}$ This program focuses on addressing individual patients' needs in collaboration with a case manager acting as a coach and ensuring the coordination with an interdisciplinary team. ${ }^{15}$ When accompanied by a case manager, COPD action plans reduce severe acute exacerbations. ${ }^{17}$ Despite these evidence, no more than one-third of primary care providers report providing a COPD action plan and most patients are not trained in self-management skills. ${ }^{18}$

Multiple barriers have been found to influence the capacity of primary care teams to offer this kind of patient-centered integrated care approach. In a qualitative study conducted in England, Ogunbayo et al identified the many factors affecting COPD self-management at the patient, practitioner and organization/system levels. ${ }^{6}$ Patient-level barriers were poor knowledge and skills, which reduce motivation to engage in behaviour changes, in addition to personal characteristics and conditions such as social support network and personal life circumstances. Practitioner-level factors were related to COPD knowledge, communication skills, teamwork and routine practice. Organizational barriers were fragmentation of COPD care services, as well as lack of care organization, communication and information-sharing infrastructure, referral pathways and self-management planning tools. Similar results were also obtained in Sweden, where improvement of COPD primary care was described as being implemented on shaky ground with unfavourable working conditions and lack of both interprofessional collaboration and professional competence and resources. ${ }^{19}$

To improve healthcare quality, more collaborative and integrated models of care have been recommended in professional society consensus statements and clinical practice guidelines related to $\mathrm{COPD}^{20-25}$ To facilitate the development and implementation of such model, the quality improvement collaborative (QIC) approach can support healthcare professionals in adopting clinical practice guidelines and quality improvements to change clinical practice, ${ }^{26-}$ ${ }^{28}$ ultimately improving outcomes and healthcare utilization. ${ }^{29}$ QICs involve multidisciplinary groups of professionals and managers who participate in a structured process to identify practice gaps and share strategies to be implemented to improve quality of services. ${ }^{28,30}$

Currently, a large-scale QIC known as COMPAS+ is being implemented in Quebec to support quality improvement of chronic disease care in primary care settings. COMPAS+ is implemented by Quebec's Ministry of Health and Social Services (MSSS) and the Institut national d'excellence en santé et en services sociaux (INESSS), which is the provincial advisor on clinical excellence in health and social care. The program's main goals are to engage primary care professionals and patients in quality improvement (QI), increase interprofessional collaboration and improve service delivery for priority chronic diseases. ${ }^{31}$ The innovation central to COMPAS+ is the way it combines the use of population-based data to provide feedback on chronic disease performance, engages participants in a process of critical 
reflection on their performance and facilitates the development of QI action plans through a collaborative problemsolving process. ${ }^{31,32}$ In the last few years, the COMPAS+ program has been improved to extend the duration of the reflective practice workshops to a full day, obtain formal institutional approval for the program from leaders in each region and create a local implementation team that now receives long-term post-workshop support from a QI expert to facilitate achievement of local QI projects. Patient partners are actively involved in the different QIC activities, which allows them to share their experiential knowledge and participate in identifying - with primary care teams and healthcare organization managers - the most important QI challenges they need to overcome to improve chronic disease management. It also allows them to voice their needs in terms of finding solutions to these problems and implementing them in practice. Between 2016 and 2019, 14 sites in four different regions of Quebec were engaged in the COMPAS+ intervention to improve the primary care services delivered to people living with COPD. The aim of this study was thus to describe the main quality problems reported by the participating teams and the strategies they proposed and implemented to improve COPD primary care services in Quebec.

\section{Study Purpose and Research Questions}

The study goal was to describe the main COPD quality problems identified and proposed changes by primary care teams in Quebec. The project aimed more specifically to answer four research questions:

1. What are the perceived problems for improving the quality of primary care services offered to people with COPD in Quebec?

2. What are the perceived main root causes explaining these quality problems in the primary care management of COPD in Quebec?

3. What are the proposed change strategies to reduce these quality gaps?

4. What strategies have been locally implemented to improve primary care COPD management?

\section{Methods}

We conducted a qualitative descriptive retrospective study ${ }^{33}$ to compare and combine the results obtained at the sites that received the COMPAS+ intervention. A COMPAS+ workshop lasts one full day and uses three main strategies to engage participants in QI: 1) a feedback intervention to interactively introduce performance indicators by relating them to the recommendations outlined in COPD clinical practice guidelines; 2) small and large group reflective exercises to achieve a shared understanding of local performance indicators and the most important quality gaps; and 3) a collaborative problem-solving and action-planning process involving small groups of 8 to 10 people who identify key COPD quality problems and their root causes, propose feasible solutions, and negotiate the content of their QI action plans. QI and change management experts, working in collaboration with the INESSS, facilitate these workshops. They also provide four facilitation follow-ups (up to 24 months post-workshop) to support local implementation of QI action plans. More details on the COMPAS + program can be obtained in previously published papers. ${ }^{31,32,34}$

A detailed report was written by the facilitators after each workshop describing a summary of participants discussions. Each report contains information on how the workshop was organized and conducted, the results of the reflective and brainstorming exercises, key COPD quality problems raised, and results of the root cause analysis. It also provided a list of proposed solutions and a description of QI action plans that were discussed between the participants during the workshop. Pictures of brainstorming and root-cause analysis exercises were taken and included in these reports. Reports were shared with local implementation teams to validate their content. Documents describing follow-up details and progress made during implementation of action plans were also analyzed. These documents take the form of detailed facilitator's notes taken during meetings with the local implementation team, as well as local action plans, usually in the form of an A3 action plan (Lean A3 form). A total of 14 workshop reports (270 participants), 31 QI action plans and 4 final reports from the last follow-up visits in each region underwent content analysis. ${ }^{35}$ All documents were uploaded into NVivo software (QSR International Pty Ltd. Version 12, 2018) and were then coded. During data condensation, key COPD quality problems raised during each COMPAS+ workshop were extracted from reports and were coded inductively. Similar problems were grouped together in order to identify the most important quality problems. Root causes for 
each main quality gaps, also identified by workshop participants, were then classified in categories using a coding tree based on the Consolidated Framework for Implementation Research domains and constructs. ${ }^{36}$ After classification within the CFIR domains and constructs, root causes were recoded and renamed to translate our results more precisely and accurately. The same coding process was used for solutions/strategies proposed by participants that were organized according to the intervention function types described in the Behavior Change Wheel (BCW). ${ }^{37,38}$ Co-coding was performed by two members of the research team (GG, BV). During data display, tables were created in Excel spreadsheets to find patterns, reduce, and compare data from each region. Three members of the team (BV, GG, IG), one workshop facilitator (VNT) and one patient partner mentor (LH) (who had attended all the COPD workshops) met three times to validate the data analysis process and the result table produced. Ethical approval for this study was obtained from the Research Ethics Committee of the Centre intégré universitaire de santé et de services sociaux de l'Est de l'île de Montréal (MP-12-2019-1760). Consent was obtained from all participating organizations to use the material related to the conduct and follow-up of the COMPAS+ program. Since analysis on these QI activities were conducted retrospectively, explicit signed consent of individual participants was not considered necessary by the REB. No personal information on participants was transmitted to the research team, and the study was considered to pose minimal risks for workshop participants. ${ }^{39}$

\section{Results}

\section{Key COPD Quality Problems and Main Root Causes}

Figure 1 shows the four perceived key COPD quality problems and their main root causes. The qualitative analysis led to an adapted version of the fishbone diagram, which represents the major causes of non-optimal primary care services for COPD. In a fishbone diagram, the fish's head represents the intended target for improvement, the ribs represent major causes, and the sub-branches represent root causes. More information on the results of the preliminary qualitative analyses based on the CFIR domains and constructs and BCW is provided in Appendix 1.

\section{Lack of Organization/Coordination of COPD Services}

Lack of organization/coordination of primary care services emerged as one of the major barriers to providing better COPD care. Major causes for this quality gap were classified into three of CFIR domains: process, intervention, and inner setting (Appendix 1). First, professionals recognized their general lack of awareness of COPD and lack of access to professional education on COPD prevention, diagnosis and management. This was also related to their lack of knowledge awareness of services available to COPD patients, such as smoking cessation and pulmonary rehabilitation services or even the regular follow-up that can be provided by community pharmacists. Participants reported the absence of resources and tools, such as a clear and defined COPD care trajectory of services, for patients in all four regions. To improve organization and coordination of services, definition of professionals' roles, such as the case management role, was considered essential to clarify. It was also considered important to increase access to tools for improving interorganizational service coordination (eg, between the hospital departments, emergency room, family medicine group and community pharmacy), and access to financial and human resources such as respiratory therapists. Furthermore, participants mentioned the need for more organizational and medical leadership and more public and healthcare professional interest in COPD.

\section{Lack of Screening Services Coordination}

Regarding coordination of COPD screening services, participants underlined the absence of a systematic screening process in primary care, at the emergency room and during hospitalization. Participants described four main causes that were related to planning, intervention, inner setting and outer setting domains of the CFIR framework (patient needs and resources) (Appendix 1). These were: 1) low professional awareness of the importance of early COPD detection and knowledge of signs and symptoms that should be screened for, 2) lack of training in COPD prevention and screening, 3) lack of resources and tools, such as availability of spirometers, screening tools or access to respiratory therapists (even 


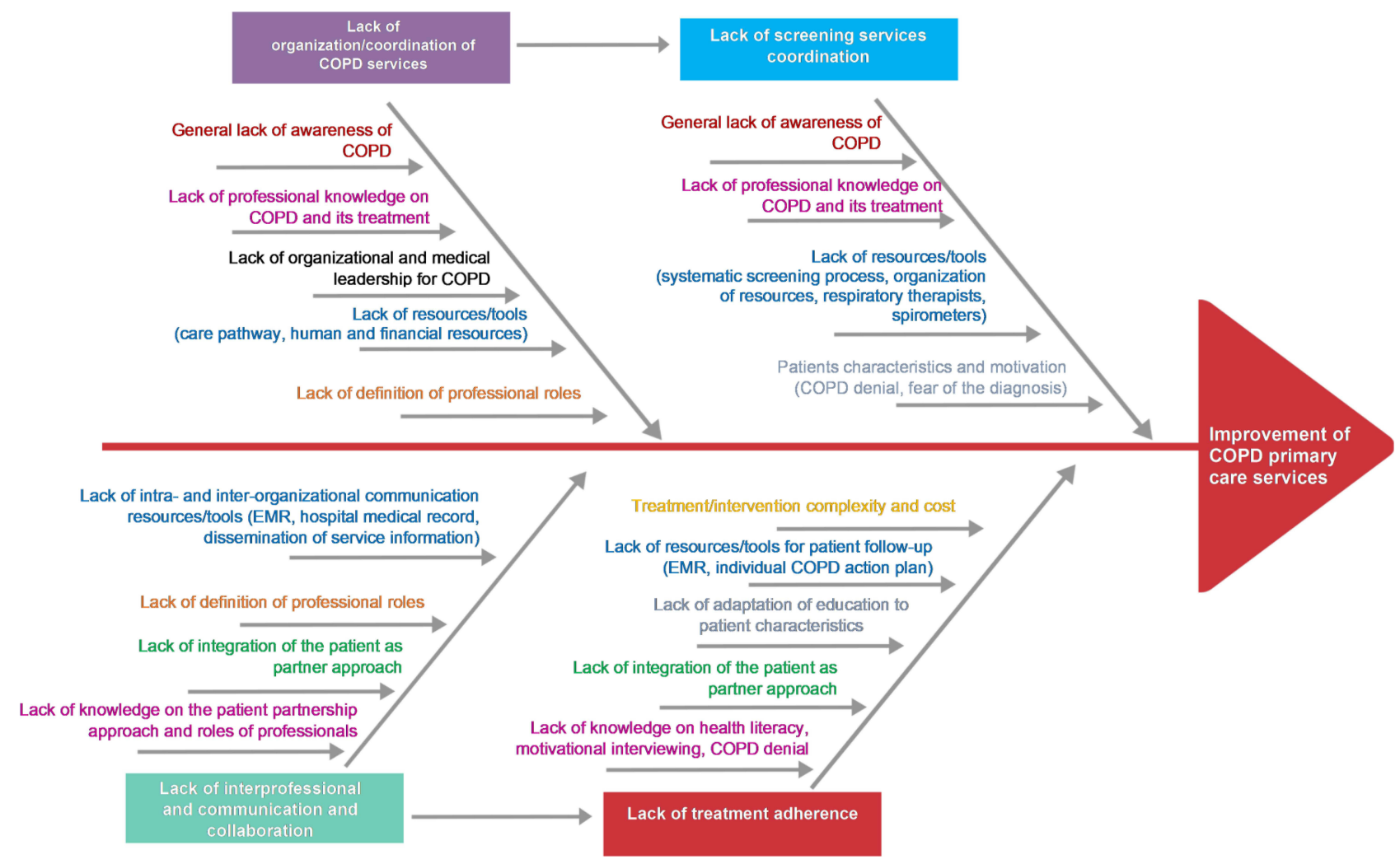

Figure I The four perceived key COPD quality problems and main root causes.

Abbreviations: COPD, chronic obstructive pulmonary disease; EMR, electronic medical record.

more difficult in rural areas), and 4) characteristics of the clientele, which is known for denying their condition or refusing to undergo screening exams due to their fear of being diagnosed and obliged to stop smoking.

\section{Lack of Interprofessional Communication and Collaboration}

Regarding this COPD quality problem, workshop participants identified three main intraorganizational and two main interorganizational root causes related to the CFIR inner setting domain (Appendix 1). The main barrier to interprofessional collaboration within primary care services (intraorganizational level) was described as lack of knowledge of the various professionals' roles. Participants from the different regions mentioned being unaware of other professionals' skills, scopes of practice and services. Working in different physical locations (eg, community pharmacists) was also considered a barrier to collaboration. In addition, patients, family and caregivers reported not being included in their interprofessional team, revealing lack of knowledge and of implementation of the client-centered and patient-as-partner approaches. ${ }^{40}$ At the interorganizational level, participants noted a major lack of dissemination of knowledge about service availability and organization and the lack of an integrated communication system across the care continuum (primary care services, hospital services, specialized COPD services, community services).

\section{Lack of Treatment Adherence}

With regard to treatment adherence (extent to which patient behaviour aligns with healthcare providers' recommendations), four main causes were identified and were classified into four CFIR domains: intervention, inner setting, planning and outer setting (patient needs and resources) (Appendix 1). First, participants described COPD self-management and treatment as complex, medication as costly and patient education as inappropriately adapted to patients', family members' and caregivers' needs. Care coordination was described as poor and attributed to lack of tools to easily access anywhere patients' COPD action plans (eg, emergency department, community pharmacy) to prevent exacerbations, lack 
of follow-up and support by professionals, lack of patients' and family members' participation in decision-making processes and design of the treatment plan. Participants also reported that healthcare professionals lacked training in the use of tools (eg motivational interviewing, patient-as-partner approach), which take into consideration patients' characteristics (such as health literacy and COPD denial) that can influence their capacity to actively engage in COPD selfmanagement (Figure 1).

\section{Proposed QI Strategies and Locally Implemented Strategies}

Participants proposed more than 142 strategies to improve the quality of COPD primary care. These strategies were first organized according to the key COPD quality problem they targeted and the category of behaviour change technique they fell under. Lastly, since quality problems shared similar main root causes, they were then reorganized according to the factors they were expected to change (Table 1). Examples of strategies implemented are also presented. Proposed strategies were classified under three categories of behaviour change techniques: education/persuasion, enablement and environmental restructuring.

\section{Education/Persuasion}

Education to primary care professionals on COPD guidelines was identified as a requirement to improve their understanding of the clinical presentation, treatment, and prevention of exacerbations. It was also deemed important to improve

Table I QI Strategies Proposed and Examples of Implemented Strategies

\begin{tabular}{|c|c|c|}
\hline Main Root Causes & General Proposed Strategies & Examples of Locally Implemented Strategies \\
\hline $\begin{array}{l}\text { General lack of awareness of } \\
\text { COPD } \\
\text { Lack of professional knowledge }\end{array}$ & $\begin{array}{l}\text { Education to improve knowledge of COPD, } \\
\text { professional roles and screening }\end{array}$ & $\begin{array}{l}\text { - Poster installed in the waiting room to educate } \\
\text { patients about the symptoms and consequences of } \\
\text { COPD } \\
\text { - Training on the program "Living well with COPD" } \\
\text { delivered to primary care professionals in one region } \\
\text { - Presentation, by a respirologist, of COPD practice } \\
\text { guidelines to primary care physicians } \\
\text { - Development of a reminder (desk placemat) for } \\
\text { physicians to disseminate information on COPD } \\
\text { screening criteria }\end{array}$ \\
\hline $\begin{array}{l}\text { Lack of definition of } \\
\text { professional roles } \\
\text { Lack of resources/tools for } \\
\text { service coordination and } \\
\text { interprofessional } \\
\text { communication }\end{array}$ & $\begin{array}{l}\text { Enablement - Develop a clinical pathway and } \\
\text { common clinical tools (forms, algorithms, collective } \\
\text { orders, decision trees) in collaboration with patients } \\
\text { Environmental restructuring - Increase resources } \\
\text { for vaccination, smoking cessation, pulmonary } \\
\text { rehabilitation, screening at strategic points in the care } \\
\text { pathway } \\
\text { Enablement - develop intra- and interorganizational } \\
\text { communication tools, including information-sharing } \\
\text { mechanisms between community pharmacies, } \\
\text { emergency rooms and hospital departments }\end{array}$ & $\begin{array}{l}\text { - Development of a clinical pathway for COPD } \\
\text { services - screening to end of life care (mapping of } \\
\text { services, revision of professional roles, planning of } \\
\text { resources) } \\
\text { - Conversion of a nurse position to a respiratory } \\
\text { therapist position } \\
\text { - Addition of respiratory therapy resources for } \\
\text { screening purposes } \\
\text { - Change of referral mode/access point for } \\
\text { spirometry } \\
\text { - Implementation of an electronic communication } \\
\text { platform for systematic follow-up of COPD patients } \\
\text { (integration of EMR and healthcare organization data) }\end{array}$ \\
\hline $\begin{array}{l}\text { Lack of integration of the } \\
\text { patient-as-partner approach } \\
\text { Lack of adaptation of patient } \\
\text { education to patients' } \\
\text { characteristics } \\
\text { Lack of resources/tools for } \\
\text { patient follow-up }\end{array}$ & $\begin{array}{l}\text { Education on the patient-as-partner approach, health } \\
\text { literacy, motivational interviewing } \\
\text { Enablement - Select or develop, with patients, } \\
\text { common educational and follow-up tools adapted to } \\
\text { patients' characteristics }\end{array}$ & $\begin{array}{l}\text { - Integration of teaching and follow-up tools from the } \\
\text { "Living well with COPD" program into the healthcare } \\
\text { organization website https://www.livingwellwithcopd. } \\
\text { com/exclusive-educational-tools.html } \\
\text { - Development of a COPD follow-up booklet in } \\
\text { collaboration with users }\end{array}$ \\
\hline
\end{tabular}


knowledge of different professionals' roles and of ways to adapt educational interventions to patient characteristics such as low health literacy or motivation levels. Education on motivational interviewing and on the patient-as-partner approach was described as essential to improving patient adherence to treatment. Educational strategies locally implemented took the form of educational meetings for primary healthcare professionals on practice guidelines recommendations or on the "Living well with COPD" program and poster advertisement for patients (poster installed in the waiting room) and reminders for physicians (screening tool in the form of a desk placemat).

\section{Enablement}

Strategies proposed by participants to address lack of service organization and coordination and lack of interprofessional communication and collaboration include strategies for increasing professional capability and environmental opportunities. The development of a COPD clinical pathway (mapping of available services, revision of professional roles and planning of resources) with the collaboration of patient partners was proposed as a solution for improving service coordination. Redefining the role of respiratory therapists and clinical nurses in screening and patient education was frequently discussed. Including community pharmacists within the care pathway was also recommended, as their contribution to patient follow-up was described as underused by other primary care professionals.

Professionals also stressed the importance of developing intra- and interorganizational communication tools to ensure timely delivery of required services to patients. Primary care professionals should be informed, in the electronic medical record (EMR), when one of their COPD patients has consulted at emergency or been hospitalized, or when the pharmacist activates a prescription from the person's COPD action plan during an acute exacerbation. Details on an electronic communication platform for systematic follow-up of COPD patients developed in one region are presented in Box 1.

Participants also cited the need for the use and sharing of common clinical tools (referral forms, algorithms, collective orders, decision tree), which should be easily accessible and would facilitate interprofessional collaboration. Even if tools, such as the COPD action plan form, are already freely available online from "Living Well with COPD program", the participating organizations and professionals appeared unaware of their existence and decided to engage in their development, a time- and resource-intensive process. Access to educational material adapted to patient characteristics, such as health literacy or readiness-to-change level, was also recommended and needs to be developed.

\section{Environmental Restructuring}

Participants further reported lack of resources as affecting the quality of COPD services. They recommended the review of available services and identification of where, in the care trajectory, patients can access these services. Increasing access to vaccination smoking cessation services, active screening (spirometry), and pulmonary rehabilitation services for all patients regardless of their geographical location was considered very important. Primary care services have limited access to respiratory therapists' services, which are not yet integrated into family medicine groups, and limited access to spirometry and could facilitate other aspects of the patient management. For example, some organizations decided to convert a nurse position to a respiratory therapist position or to increase resources in respiratory therapy (Table 1).

Different projects targeted different priorities and sharing these teams' experiences can help guide the improvement of COPD services in other organizations. This is important if the healthcare system is to stop "reinventing the wheel" and

\section{Box I Electronic Communication Platform For Systematic Follow-Up Of COPD Patients}

An electronic communication platform was created and is now available to family medicine groups, the hospital and community care centres to allow the follow-up of patients diagnosed with COPD. It provides information on the patient's primary healthcare professionals and details on their COPD action plan, such as all the information concerning the management of acute exacerbations, to allow for real-time follow-up. For example, in the event of an exacerbation, a list of tasks is automatically sent to the targeted professionals to ensure follow-up after 48 hours of antibiotics or prednisone. Any changes made to the patient's record can be consulted from all sites. This database was developed from a pre-existing database for monitoring patients on anticoagulants. 
improve its capability to adapt, adopt and use available knowledge, programs, tools and resources, especially when they have been shown to be acceptable and effective for COPD patients.

\section{Discussion}

This study identified the main quality problems involved and strategies for improving COPD primary care services in Quebec as a part of the COMPAS+ program. As mentioned by Halpin et al, ${ }^{41}$ it is time to take COPD seriously and raise awareness of this disease among healthcare professionals and the public. Improving COPD management in primary care poses multiple challenges. Interestingly, our study results are very similar to those obtained in other countries such as in England, ${ }^{42}$ Sweden, ${ }^{19}$ and the United States. ${ }^{5}$ One specific and very significant problem related to lack of adherence to COPD guidelines is the generalized lack of knowledge and initial training of primary care physicians and other allied health professionals. ${ }^{43}$ Providing continuing professional education on COPD is essential for QI of COPD primary care services. ${ }^{9,44,45}$ However, lack of interest in COPD limits attendance at educational and practice change interventions. In a qualitative study of 59 primary care providers in Sweden, Sandelowsky et $\mathrm{a}^{46}$ found that lack of COPD awareness and of concern due to its clinical features were major factors in COPD's deprioritization in clinical practice compared to other medical conditions perceived as more urgent. The same authors also found that continuing medical education (CME) provided to physicians led to only modest improvements at 12-month follow-up and that common educational methods may be insufficient to improve COPD management in general practice. ${ }^{46}$ To be effective, CME programs need to use diverse interactive, dynamic, collaborative and interdisciplinary learning methods to improve not only clinicians' knowledge of COPD but also their self-confidence and skills in implementing GOLD report' recommendations, such as using and interpreting spirometry results, prescribing and providing patients with appropriate self-management education and support. ${ }^{44,45}$ Gagné et $\mathrm{al}^{47}$ demonstrated, in a Quebec-based study, that a 7-hour training session, delivered to experienced respiratory educators (trained respiratory therapists or nurses), led to major clinical improvements in patient quality of life, health-directed behaviours, and skills and techniques in everyday practice. However, challenges related to assessing each patient's educational needs, actively engaging them in their learning process and tailoring the intervention to their needs remained. Nevertheless, this CME program is easily accessible and could be more widely implemented at the provincial and national level to increase primary care teams' competencies in delivering optimal COPD care and self-management education.

The need to inform the public of COPD's prevalence, importance and serious consequences for individuals' functional capacities was also emphasized by our study participants. Low public awareness of COPD has been documented in previous studies, which reported that current, ex- and non-smokers knew very little about the aetiology, symptoms and severity of COPD, which is a preventable disease. ${ }^{3,48,49}$ In a Korean study, authors demonstrated that a television mass media campaign could increase awareness of COPD and COPD-related symptoms and of the importance of smoking cessation willingness among subjects. ${ }^{48}$ Although few studies have evaluated this type of intervention, a Cochrane systematic review has shown that mass media campaigns are effective in inducing changes in the use of health services. ${ }^{50}$ Other studies have also demonstrated their effectiveness in improving awareness of the signs and symptoms of stroke ${ }^{51}$ and beliefs about back pain management. ${ }^{52}$ Such campaigns have the added benefit of reaching the general population, those at risk and healthcare professionals at large, which can induce practice change by influencing multiple stakeholders.

Lack of service organization and coordination were found to be other main barriers to improving COPD services. Participants from the four regions described not being fully aware of services available for patients within the continuum of care, including access to diagnostic, treatment and self-management services, and that these were not appropriately organized. In a study conducted in England, primary care clinicians also reported inconsistency in referral pathways and wide variations in self-management planning tools. ${ }^{6}$ Developing a COPD care pathway was chosen as a priority QI strategy by multiple healthcare organizations participating in this study. This may be an appropriate choice since a recent systematic review suggested that care pathways for COPD could potentially reduce readmissions, complications, and length of stays, but not improve quality of life or decrease mortality. ${ }^{53}$ It should nevertheless be noted that developing and implementing care pathways is costly and very time-consuming and can require considerable resources. ${ }^{52}$ What was observed throughout the COMPAS+ experience is that multiple healthcare organizations felt they first had to revise their 
COPD service offer and consult experts and clinicians before designing or adapting their own care pathway, which usually demands considerable time and effort. We believe, instead, that a COPD care pathway model should be developed at the provincial level, based on best clinical guidelines and characteristics of Quebec's healthcare system, and provide clear recommendations on the care and services that should be available to all COPD patients across the care continuum. This model could be disseminated to all healthcare organizations for local adoption, implementation and adaption to their specific context and available resources. We believe repeating this process in every healthcare organization in the province is inefficient and likely a waste of precious resources. In QI, it is first important to identify best practices and how other teams have addressed similar improvement challenges, and then to adapt and innovate to improve results and avoid the risk of "reinventing the wheel". 54

Furthermore, systematic COPD active screening needs to be integrated into the COPD care pathway, as our findings showed that the absence of systematic screening was due to lack of service organization and coordination. In Canada, only $56 \%$ of primary care physicians reported that their COPD patients had ever undergone spirometry testing, ${ }^{55}$ clearly illustrating the underutilization of pulmonary function tests to confirm a COPD diagnosis in primary care. Spirometry underutilization is generally a persistent practice gap despite its accessibility. ${ }^{56}$ Studies attributed spirometry underutilization to lack of knowledge of spirometry testing procedures or of how to interpret the results. ${ }^{56,57}$ Again, investing in educational interventions on COPD screening and spirometry for primary care professionals, in addition to increasing resources and facilitating interprofessional collaboration with respiratory therapists or trained COPD nurses, are promising solutions. ${ }^{58,59}$ Chen et al reported a vast increase improvement in requests for spirometry screening after delivering a multifaceted educational intervention to physicians that emphasized the importance of spirometry, and to nurses on how to perform spirometry tests correctly combined with increased accessibility to spirometry equipment. ${ }^{60}$

Interprofessional collaboration and communication were also identified as a major barrier to improving the quality of COPD services. The roles of the different healthcare team members have been described as unclear, and lack of knowledge about each professional's specific contribution to COPD management cited as a challenge to interprofessional collaboration. ${ }^{19}$ Nurses often report that they lack knowledge to support COPD patients compared to diabetes management, and respiratory therapists are not yet fully integrated into primary care teams. Well-trained professionals with clearly defined roles and greater integration of respiratory therapists into family medicine groups could facilitate access and referral to more adequate patient care ${ }^{61,62}$ Community pharmacists should also be key-members of primary care teams, yet are often the forgotten players. These pharmacists are ideally placed to provide regular and frequent education on smoking cessation, COPD, medication adherence, appropriate inhaler technique, recognition of COPD exacerbation symptoms and action plan ownership and follow-up. ${ }^{63-65}$ A systematic review conducted in 2014 found that pharmacists' interventions effectively improved medication adherence and reduced hospital admissions and health-related costs, and should be considered a potent strategy for managing COPD outpatients. ${ }^{63,66}$ Their role should thus be spelled out within recommended care pathways. Furthermore, in other countries, such as Sweden and Germany, integrated COPD care is also provided with the collaboration of physiotherapists, occupational therapists and nutritionists, who are considered important for improving patients' self-management of healthy nutrition and weight loss, coughing management, physical activity and participation in daily activities. ${ }^{67}$ Restructuring COPD primary care services should thus facilitate access, referrals and teamwork between primary care physicians, nurses, respiratory therapists, pharmacists and other allied health professionals.

Since appropriate management of exacerbations is one of the main challenges of COPD management, establishing an effective communication system that facilitates the transmission of information between the emergency room, hospital departments and primary care is essential. ${ }^{6,67}$ One region participating in the COMPAS+ intervention implemented an innovative communication system linking together the family medicine groups and hospital EMRs and created alerts to make all professionals aware of the patient's journey through the care continuum. Discharge follow-up interventions of any kind for COPD patients have proven effective in preventing hospital readmissions. ${ }^{68}$ Nevertheless, these interventions, rather than creating links with primary care and community services, are still often implemented within hospital services and do not support appropriate longer term follow-up to prevent future exacerbations and integrated care delivery by the patient's own healthcare team. ${ }^{68}$ 
Lack of integration of the patient-as-partner approach $^{40}$ and of patient education adapted to patients' characteristics $^{67,69}$ were considered the root causes of several QI challenges. As mentioned by Moreo, ${ }^{5}$ there is more and more evidence that patients who are engaged as partners in their health care experience better outcomes at lower costs and that perceptions of the quality of their COPD care are correlated with the collaboration they have with their providers. ${ }^{70}$ The chronic nature of COPD requires patients to manage their changing condition over time to optimize their quality of life ${ }^{71}$ and avoid health deterioration. ${ }^{72}$ Multiple studies have showed that self-management education, such as the "Living well with COPD" program, ${ }^{14,73,74}$ can significantly decrease the rate of emergency-room visits and hospitalizations for acute COPD exacerbations. ${ }^{14,75-79}$ However, the educational interventions provided vary greatly, and individualization of education is warranted to ensure better health outcomes. ${ }^{69}$ Ensuring that professionals have the competencies to support the patient's active role and engagement in COPD self-management requires listening skills, empathy, motivational interviewing skills and the ability to adapt the intervention to the patient's coping style ${ }^{67,69}$ One solution suggested by the study participants and their organization was to develop new patient education tools rather than adopting, adapting and using those already available. As highlighted by Papadakos et al ${ }^{80}$ a similar situation exists in cancer education programs, where significant duplication of efforts was found to influence costs and the quality of educational material. Creating a mechanism for sharing existing self-management programs, such as making material available on a website and providing clear incentives for using it, is essential and could result in significant cost savings. More centralized and coordinated efforts could also provide more opportunities for patient education experts and partners to review educational tools and ensure that they are adapted to the educational and health literacy levels of different patient groups and kept up-to-date. ${ }^{80}$ Future work needs to focus on how to better coordinate these efforts at the policy level to avoid unnecessary duplication of COPD patient education tools and programs.

\section{Conclusion}

Quality improvement collaboratives activities can lead to the identification and deep understanding of quality improvement challenges healthcare organizations and professionals face to improve primary care services. This study shed light on the ways in which it is possible to use this information to formulate priorities and strategies to improve COPD services in Quebec (Canada) and how the COMPAS+ program contributes to the development of a learning health system enabling cycles of continuous learning and improvements that can be embedded within the system. ${ }^{81}$ This study presents multiple strengths: multiple regions participated to the intervention and an important number of professionals were engaged in the COMPAS+ workshops. Providing feedback using administrative data, engaging participants in reflection on their practice and supporting local QI teams to implement QI strategies contributed to the richness of the data analyzed. However, limitation of this study is related to the fact that recommended QI strategies were proposed following brainstorming and few of them were fully implemented and evaluated. Furthermore, QI action plans were described in detail, but it was sometimes difficult to make a clear difference between what was planned and what was implemented in practice. A multiple mixed case study is now being conducted to assess the effectiveness of the COMPAS+ QIC and will help us document to what extent practice changes were really implemented. Regions where the COPD COMPAS+ intervention was delivered were rural or suburban and we cannot thus be sure that no other COPD QI problems would have been found in an urban area, such as the Montreal region, where care organization presents even more complex challenges. However, the similarities between our results and those of other studies conducted in other countries are supporting the possible generalizability of our results to other contexts. Priorities identified and strategies formulated within this paper will support the pursue of the COMPAS+ program directed towards the improvement of COPD primary care services.

\section{Abbreviations}

COMPAS, Collectif pour les Meilleures Pratiques et l'Amélioration des Soins et Services; COPD, chronic obstructive pulmonary disease; INESSS, Institut national d'excellence en santé et services sociaux (Quebec's excellence institute in healthcare and social services); QI, quality improvement; QIC, quality improvement collaborative. 


\section{Acknowledgments}

We would like to thank the Quebec's Ministry of Health and Social Services and all members of the COMPAS+ project team working at the INESSS responsible of the implementation of the intervention, especially Denis Roy, Carl Drouin and Isabelle Ganache. We would also like to thank Marie-Claude Fournier (Convergence Santé) for facilitating the COMPAS + workshops and all participants, including patient partners, who attended the workshops and the follow-up intervention. This study was funded by the Canadian Institutes of Health Research (Grant Reference Number 159486). The content is solely the responsibility of the authors and does not necessarily represent the official views of the Quebec's Ministry of Health and Social Services and the INESSS.

\section{Disclosure}

Dr Jean Bourbeau reports grants from CIHR, grants from FRQS, Foundation of the McGill University Health Centre and Distinguished Scientist Award of McGill University. He reports grants, articipating in speaking activities and advisory board for AstraZeneca Canada Ltd, Boehringer Ingelheim Canada Ltd, GlaxoSmithKline Canada Ltd and Global, Pfizer Canada Ltd and Trudell Canada Ltd. He reports being a member of Formulary or similar Committee for INESS (province of Quebec), Provincial Lung Associations (Quebec and Ontario), Canadian Thoracic Society (CTS) and Global Initiative of Obstructive Lung Disease (GOLD) outside the submitted work. The authors report no other conflicts of interest in this work.

\section{References}

1. World Health Organisation. Chronic obstructive pulmonary disease (COPD); 2019. Available from: http://www.who.int/respiratory/copd/en/. Accessed January 19, 2022.

2. Public Health Agency of Canada. How Healthy are Canadians? A Trend Analysis of the Health of Canadians from a Healthy Living and Chronic Disease Perspective. Ottawa, ON: Public Health Agency of Canada; 2016.

3. Boehm A, Pizzini A, Sonnweber T, et al. Assessing global COPD awareness with google trends. Eur Respir J. 2019;53(6):1900351. doi:10.1183/ 13993003.00351-2019

4. Statistics Canada. Chronic obstructive pulmonary disease under-diagnosed in Canadian adults: results from cycles 3 and 4 (2012 to 2015) of the Canadian health measures survey. Health Fact Sheets 2017; 2021. Available from: https://www150.statcan.gc.ca/n1/pub/82-625-x/2017001/article/ 14701-eng.htm. Accessed August 03, 2021.

5. Moreo K, Greene L, Sapir T. Improving interprofessional and coproductive outcomes of care for patients with chronic obstructive pulmonary disease. BMJ Open Qual. 2016;5(1):u210329.w214679.

6. Ogunbayo OJ, Russell S, Newham JJ, et al. Understanding the factors affecting self-management of COPD from the perspectives of healthcare practitioners: a qualitative study. NPJ Prim Care Respir Med. 2017;27(1):1-9. doi:10.1038/s41533-017-0054-6

7. Criner RN, Han MK. COPD care in the 21st century: a public health priority. Respir Care. 2018;63(5):591-600. doi:10.4187/respcare.06276

8. Yawn BP, Mintz ML, Doherty DE. GOLD in practice: chronic obstructive pulmonary disease treatment and management in the primary care setting. Int J Chron Obstruct Pulmon Dis. 2021;16:289-299. doi:10.2147/COPD.S222664

9. Sehl J, O'Doherty J, O'Connor R, O’Sullivan B, O'Regan A. Adherence to COPD management guidelines in general practice? A review of the literature. Ir J Med Sci. 2018;187(2):403-407. doi:10.1007/s11845-017-1651-7

10. Albitar HAH, Iyer VNI. Adherence to global initiative for chronic obstructive lung disease guidelines in the real world: current understanding, barriers, and solutions. Curr Opin Pulm Med. 2020;26(2):149-154. doi:10.1097/MCP.0000000000000655

11. Boulet LP, Bourbeau J, Skomro R, Gupta S. Major care gaps in asthma, sleep and chronic obstructive pulmonary disease: a road map for knowledge translation. Can Respir J. 2013;20(4):265-269. doi:10.1155/2013/496923

12. Qureshi H, Sharafkhaneh A, Hanania NA. Chronic obstructive pulmonary disease exacerbations: latest evidence and clinical implications. Ther $A d v$ Chronic Dis. 2014;5(5):212-227. doi:10.1177/2040622314532862

13. Ragaišienė G, Kibarskyte R, Gauronskaite R, et al. Diagnosing COPD in primary care: what has real life practice got to do with guidelines? Multidiscip Respir Med. 2019;14(1):1-7. doi:10.4081/mrm.2019.28

14. Bourbeau J, Julien M, Maltais F, et al. Reduction of hospital utilization in patients with chronic obstructive pulmonary disease: a disease-specific self-management intervention. Arch Intern Med. 2003;163(5):585-591. doi:10.1001/archinte.163.5.585

15. Bourbeau J, Farias R, Li PZ, et al. The Quebec respiratory health education network: integrating a model of self-management education in COPD primary care. Chron Respir Dis. 2018;15(2):103-113. doi:10.1177/1479972317723237

16. Bourbeau J, Nault D, Dang-Tan T. Self-management and behaviour modification in COPD. Patient Educ Couns. 2004;52(3):271-277. doi:10.1016/ S0738-3991(03)00102-2

17. Bourbeau J, Echevarria C. Models of care across the continuum of exacerbations for patients with chronic obstructive pulmonary disease. Chron Respir Dis. 2020;17:1479973119895457. doi:10.1177/1479973119895457

18. Roberts CM, Stone RA, Buckingham RJ, Pursey NA, Lowe D, Potter JM. A randomized trial of peer review: the UK national chronic obstructive pulmonary disease resources and outcomes project: three-year evaluation. J Eval Clin Pract. 2012;18(3):599-605. doi:10.1111/j.13652753.2011.01639.x

19. Lundell S, Tistad M, Rehn B, Wiklund M, Holmner Å, Wadell K. Building COPD care on shaky ground: a mixed methods study from Swedish primary care professional perspective. BMC Health Serv Res. 2017;17(1):1-14. doi:10.1186/s12913-017-2393-y 
20. Rocker G, Downar J, Morrison RS. Palliative care for chronic illness: driving change. CMAJ. 2016;188(17-18):E493-E498. doi:10.1503/ cmaj. 151454

21. Rocker GM, Simpson AC, Horton R. Palliative care in advanced lung disease: the challenge of integrating palliation into everyday care. Chest. 2015;148(3):801-809. doi:10.1378/chest.14-2593

22. Cawley D, Billings J, Oliver D, Kendall M, Pinnock H. Potential triggers for the holistic assessment of people with severe chronic obstructive pulmonary disease: analysis of multiperspective, serial qualitative interviews. BMJ Support Palliat Care. 2014;4(2):152-160. doi:10.1136/ bmjspcare-2013-000629

23. Epiphaniou E, Shipman C, Harding R, et al. Coordination of end-of-life care for patients with lung cancer and those with advanced COPD: are there transferable lessons? A longitudinal qualitative study. Prim Care Respir J. 2014;23(1):46-51. doi:10.4104/pcrj.2014.00004

24. Marciniuk DD, Goodridge D, Hernandez P, et al. Managing dyspnea in patients with advanced chronic obstructive pulmonary disease: a Canadian Thoracic Society clinical practice guideline. Can Respir J. 2011;18(2):69-78. doi:10.1155/2011/745047

25. Hanania NA, Marciniuk DD. A unified front against COPD: clinical practice guidelines from the American College of Physicians, the American College of Chest Physicians, the American Thoracic Society, and the European Respiratory Society. Chest. 2011;140(3):565-566. doi:10.1378/ chest.11-1152

26. Verma JY, Rossiter M, Kirvan K, et al. Going far together: healthcare collaborations for innovation and improvement in Canada. Int $J$ Healthc Manag. 2013;6(2):66-76. doi:10.1179/2047971913Y.0000000029

27. Nadeem E, Olin SS, Hill LC, Hoagwood KE, Horwitz SM. Understanding the components of quality improvement collaboratives: a systematic literature review. Milbank Q. 2013;91(2):354-394. doi:10.1111/milq.12016

28. Schouten LM, Hulscher ME, van Everdingen JJ, Huijsman R, Grol RP. Evidence for the impact of quality improvement collaboratives: systematic review. BMJ. 2008;336(7659):1491-1494. doi:10.1136/bmj.39570.749884.BE

29. Verma JY, Amar C, Sibbald S, Rocker GM. Improving care for advanced COPD through practice change: experiences of participation in a Canadian spread collaborative. Chron Respir Dis. 2018;15(1):5-18. doi:10.1177/1479972317712720

30. Hulscher ME, Schouten LM, Grol RP, Buchan H. Determinants of success of quality improvement collaboratives: what does the literature show? BMJ Qual Saf. 2013;22(1):19-31. doi:10.1136/bmjqs-2011-000651

31. Vachon B, Désorcy B, Camirand M, et al. Engaging primary care practitioners in quality improvement: making explicit the program theory of an interprofessional education intervention. BMC Health Serv Res. 2013;13(1):1-12. doi:10.1186/1472-6963-13-106

32. Vachon B, Désorcy B, Gaboury I, et al. Combining administrative data feedback, reflection and action planning to engage primary care professionals in quality improvement: qualitative assessment of short term program outcomes. BMC Health Serv Res. 2015;15(1):1-8. doi:10.1186/s12913-015-1056-0

33. Sandelowski M. Whatever happened to qualitative description? J Res Nurs Health Aff. 2000;23(4):334-340. doi:10.1002/1098-240X(200008) 23:4<334::AID-NUR9>3.0.CO;2-G

34. Pomey M-P, Menear M, Drouin C, Saba T, Roy D. Amélioration des soins et des services en première ligne pour la gestion des maladies chroniques: le programme COMPAS+ au Québec. Rev Fr Aff Soc. 2020;1(1):325-335. doi:10.3917/rfas.201.0325

35. Miles MB, Huberman AM, Saldana J. Qualitative Data Analysis: A Methods Sourcebook. 3rd ed. Thousand Oaks, CA: Sage Publications; 2014.

36. Damschroder LJ, Aron DC, Keith RE, Kirsh SR, Alexander JA, Lowery JC. Fostering implementation of health services research findings into practice: a consolidated framework for advancing implementation science. Implement Sci. 2009;4(1):50. doi:10.1186/1748-5908-4-50

37. Michie S, Atkins L, West R. The Behaviour Change Wheel. A Guide to Designing Interventions. London: Silverback Publishing; 2014.

38. Michie S, van Stralen MM, West R. The behaviour change wheel: a new method for characterising and designing behaviour change interventions. Implement Sci. 2011;6:42. doi:10.1186/1748-5908-6-42

39. Hall S, Lee V, Haase K. Exploring the challenges of ethical conduct in quality improvement projects. Can Oncol Nurs J. 2020;30(1):64-68.

40. Karazivan P, Dumez V, Flora L, et al. The patient-as-partner approach in health care: a conceptual framework for a necessary transition. Acad Med. 2015;90(4):437-441. doi:10.1097/ACM.0000000000000603

41. Halpin DM, Celli BR, Criner GJ, et al. It is time for the world to take COPD seriously: a statement from the GOLD board of directors. Eur Respir J. 2019;54(1):1-5. doi:10.1183/13993003.00914-2019

42. Young HM, Apps LD, Harrison SL, Johnson-Warrington VL, Hudson N, Singh SJ. Important, misunderstood, and challenging: a qualitative study of nurses' and allied health professionals' perceptions of implementing self-management for patients with COPD. Int J Chron Obstruct Pulmon Dis. 2015;10:1043. doi:10.2147/COPD.S78670

43. Mohigefer J, Calero-Acuña C, Marquez-Martin E, Ortega-Ruiz F, Lopez-Campos JL. Understanding of COPD among final-year medical students. Int J Chron Obstruct Pulmon Dis. 2018;13:131. doi:10.2147/COPD.S138539

44. Adams SG, Pitts J, Wynne J, et al. Effect of a primary care continuing education program on clinical practice of chronic obstructive pulmonary disease: translating theory into practice. Mayo Clin Proc. 2012;87(9):862-870. doi:10.1016/j.mayocp.2012.02.028

45. Drexel C, Jacobson A, Hanania NA, Whitfield B, Katz J, Sullivan T. Measuring the impact of a live, case-based, multiformat, interactive continuing medical education program on improving clinician knowledge and competency in evidence-based COPD care. Int J Chron Obstruct Pulmon Dis. 2011;6:297. doi:10.2147/COPD.S18257

46. Sandelowsky H, Hylander I, Krakau I, Modin S, Ställberg B, Nager A. Time pressured deprioritization of COPD in primary care: a qualitative study. Scand J Prim Health Care. 2016;34(1):55-65. doi:10.3109/02813432.2015.1132892

47. Gagné M, Lauzier S, Babineau-Therrien J, et al. COPD-specific self-management support provided by trained educators in everyday practice is associated with improved quality of life, health-directed behaviors, and skill and technique acquisition: a convergent embedded mixed-methods study. The Patient-Patient-Centered Outcomes Research. 2020;13(1):103-119. doi:10.1007/s40271-019-00386-7

48. Seo JY, Hwang YI, Mun SY, et al. Awareness of COPD in a high risk Korean population. Yonsei Med J. 2015;56(2):362-367. doi:10.3349/ ymj.2015.56.2.362

49. Sikjær MG, Hilberg O, Fløe A, Dollerup J, Løkke A. Lack of awareness towards smoking-related health risks, symptoms related to COPD, and attitudinal factors concerning smoking: an Internet-based survey conducted in a random sample of the Danish general population. Eur Clin Respir J. 2018;5(1):1506235. doi:10.1080/20018525.2018.1506235

50. Grilli R, Ramsay C, Minozzi S. Mass media interventions: effects on health services utilisation. Cochrane Database Syst Rev. $2002 ;(1): C D 000389$. doi: $10.1002 / 14651858 . C D 000389$ 
51. Lecouturier J, Rodgers H, Murtagh MJ, White M, Ford GA, Thomson RG. Systematic review of mass media interventions designed to improve public recognition of stroke symptoms, emergency response and early treatment. BMC Public Health. 2010;10:1-10. doi:10.1186/1471-2458-10784

52. Suman A, Armijo-Olivo S, Deshpande S, et al. A systematic review of the effectiveness of mass media campaigns for the management of low back pain. Disabil Rehabil. 2021;43(24):3523-3551. doi:10.1080/09638288.2020.1743777

53. Plishka CT, Rotter T, Penz ED, et al. Effects of clinical pathways for COPD on patient, professional, and systems outcomes: a systematic review. Chest. 2019;156(5):864-877. doi:10.1016/j.chest.2019.04.131

54. The Health Foundation. Quality Improvement Made Simple: What Everyone Should Know About Healthcare Quality Improvement: Quick Guide. 3rd ed. London: Health Foundation; 2021.

55. Bourbeau J, Sebaldt RJ, Day A, et al. Practice patterns in the management of chronic obstructive pulmonary disease in primary practice: the CAGE study. Can Respir J. 2008;15(1):13-19. doi:10.1155/2008/173904

56. Joo MJ, Sharp LK, Au DH, Lee TA, Fitzgibbon ML. Use of spirometry in the diagnosis of COPD: a qualitative study in primary care. COPD. 2013;10(4):444-449. doi:10.3109/15412555.2013.766683

57. Haroon S, Jordan RE, Fitzmaurice DA, Adab P. Case finding for COPD in primary care: a qualitative study of the views of health professionals. Int J Chron Obstruct Pulmon Dis. 2015;10:1711. doi:10.2147/COPD.S84247

58. Tunsäter A, Moutakis M, Borg S, Persson U, Strömberg L, Nielsen AL. Retrospective incremental cost analysis of a hospital-based COPD disease management programme in Sweden. Health Policy (New York). 2007;81(2-3):309-319. doi:10.1016/j.healthpol.2006.05.013

59. Overington JD, Huang YC, Abramson MJ, et al. Implementing clinical guidelines for chronic obstructive pulmonary disease: barriers and solutions. J Thorac Dis. 2014;6(11):1586. doi:10.3978/j.issn.2072-1439.2014.11.25

60. Chen XC, Leung SH, Li YC. Chronic obstructive pulmonary disease (COPD) management in the community: how could primary care team contribute? BMC Fam Pract. 2020;21(1):1-8. doi:10.1186/s12875-020-01256-0

61. Hartford W, Asgarova S, MacDonald G, Berger M, Cristancho S, Nimmon L. Macro and meso level influences on distributed integrated COPD care delivery: a social network perspective. BMC Health Serv Res. 2021;21(1):1-11. doi:10.1186/s12913-021-06532-y

62. Slack CL, Hayward K, Markham AW. The Calgary COPD \& asthma program: the role of the respiratory therapy profession in primary care. Can $J$ Respir Ther. 2018;54(4):86-91. doi:10.29390/cjrt-2018-018

63. Twigg MJ, Wright DJ. Community pharmacy COPD services: what do researchers and policy makers need to know? Integr Pharm Res Pract. 2017;6:53. doi:10.2147/IPRP.S105279

64. Fathima M, Bawa Z, Mitchell B, Foster J, Armour C, Saini B. COPD management in community pharmacy results in improved inhaler use, immunization rate, COPD action plan ownership, COPD knowledge, and reductions in exacerbation rates. Int J Chron Obstruct Pulmon Dis. 2021;16:519. doi:10.2147/COPD.S288792

65. van der Molen T, van Boven JF, Maguire T, Goyal P, Altman P. Optimizing identification and management of COPD patients-reviewing the role of the community pharmacist. Br J Clin Pharmacol. 2017;83(1):192-201. doi:10.1111/bcp.13087

66. Zhong H, Ni X-J, Cui M, Liu X-Y. Evaluation of pharmacist care for patients with chronic obstructive pulmonary disease: a systematic review and meta-analysis. Int J Clin Pharm. 2014;36(6):1230-1240. doi:10.1007/s11096-014-0024-9

67. Koolen EH, van der Wees PJ, Westert GP, Dekhuijzen R, Heijdra YF, Van't Hul AJ. The COPDnet integrated care model. Int J Chron Obstruct Pulmon Dis. 2018;13:2225. doi:10.2147/COPD.S150820

68. Ospina MB, Mrklas K, Deuchar L, et al. A systematic review of the effectiveness of discharge care bundles for patients with COPD. Thorax. 2017;72(1):31-39. doi:10.1136/thoraxjnl-2016-208820

69. Stoilkova-Hartmann A, Franssen FM, Augustin IM, Wouters EF, Barnard KD. COPD patient education and support-Achieving patient-centredness. Patient Educ Couns. 2018;101(11):2031-2036. doi:10.1016/j.pec.2018.05.024

70. Greene J, Hibbard JH, Sacks R, Overton V, Parrotta CD. When patient activation levels change, health outcomes and costs change, too. Health Aff. 2015;34(3):431-437. doi:10.1377/hlthaff.2014.0452

71. Zwerink M, Brusse-Keizer M, van der Valk PD, et al. Self management for patients with chronic obstructive pulmonary disease. Cochrane Database Syst Rev. 2014;2014(3):CD002990.

72. Roughead E, Semple S. Second National Report on Patient Safety: Improving Medication Safety; 2002.

73. Frei A, Strassmann A, Guler M, et al. Implementation evaluation of the "Living well with COPD" self-management program in Switzerland. Eur Respir J. 2020;56:839.

74. Bischoff EW, Hamd DH, Sedeno M, et al. Effects of written action plan adherence on COPD exacerbation recovery. Thorax. 2011;66(1):26-31. doi:10.1136/thx.2009.127621

75. Gadoury M, Schwartzman K, Rouleau M, et al. Self-management reduces both short-and long-term hospitalisation in COPD. Eur Respir J. 2005;26 (5):853-857. doi:10.1183/09031936.05.00093204

76. Casas A, Troosters T, Garcia-Aymerich J, et al. Integrated care prevents hospitalisations for exacerbations in COPD patients. Eur Respir J. 2006;28 (1):123-130. doi:10.1183/09031936.06.00063205

77. Effing T, Monninkhof EE, van der Valk PP, et al. Self-management education for patients with chronic obstructive pulmonary disease. Cochrane Database Syst Rev. 2007;17(4):CD002990.

78. McCarthy B, Casey D, Devane D, Murphy K, Murphy E, Lacasse Y. Pulmonary rehabilitation for chronic obstructive pulmonary disease. Cochrane Database Syst Rev. 2015;23(2):CD003793.

79. Steurer-Stey C, Dalla Lana K, Braun J, Ter Riet G, Puhan MA. Effects of the "Living well with COPD" intervention in primary care: a comparative study. Eur Respir J. 2018;51(1):1701375. doi:10.1183/13993003.01375-2017

80. Papadakos J, Giannopoulos E, Forbes L, et al. Reinventing the wheel: the incidence and cost implication of duplication of effort in patient education materials development. Patient Educ Couns. 2021;104(6):1398-1405. doi:10.1016/j.pec.2020.11.017

81. Menear M, Blanchette M-A, Demers-Payette O, Roy D. A framework for value-creating learning health systems. Health Res Policy Syst. 2019;17 (1):79. doi:10.1186/s12961-019-0477-3 


\section{Publish your work in this journal}

The International Journal of COPD is an international, peer-reviewed journal of therapeutics and pharmacology focusing on concise rapid reporting of clinical studies and reviews in COPD. Special focus is given to the pathophysiological processes underlying the disease, intervention programs, patient focused education, and self management protocols. This journal is indexed on PubMed Central, MedLine and CAS. The manuscript management system is completely online and includes a very quick and fair peer-review system, which is all easy to use. Visit http://www. dovepress.com/testimonials.php to read real quotes from published authors.

Submit your manuscript here: https://www.dovepress.com/international-journal-of-chronic-obstructive-pulmonary-disease-journal 